Методические подходы

к использованию данных

дистанционного зондирования Земли

при осуществлении государственного

мониторинга воспроизводства лесов

\author{
(C) М.В. Чернов, С.М. Ханов
}

\title{
Methodical approaches to the use of Earth remote sensing data in the implementation of state monitoring of forest reproduction
}

M.V. Chernov, S.M. Khanov (Saint Petersburg Forestry Research Institute)

Reproduction of forest resources should be carried out in the shortest possible time by the most effective methods in forestry, environmental and economic relations, taking into account the rational use of forest lands; improving the productivity and quality of forests; ensuring optimal forest area, improving water protection, protection, sanitation and other useful properties of forests to perform their environmental protection and environmental functions.

Reforestation - the activity of restoration of cut, dead and damaged forest plantations is regulated by the reforestation Rules approved by the Order of the Ministry of natural resources of Russia dated 26.06.2016 № 375 .

According to article 61.1 of the Forest code of the Russian Federation on February 19, 2015 the order of the Ministry of natural resources of Russia No. 59 approved "the Order of implementation of the state monitoring of reproduction of the woods and there was a need for development of technical requirements to materials of remote sensing of the Earth for the solution of tasks of the state monitoring of reproduction of the woods". Previously, remote sensing of the Earth in order to assess the progress of forest reproduction in the Russian Federation was practically not used. 
State monitoring of forest reproduction (GMVL), which was first carried out in 2015, is carried out through observation using ground, aviation or space-based means, as well as through the collection and analysis of information on forest reproduction. Currently, GMVL is part of the state environmental monitoring (state environmental monitoring) and that the Procedure for its implementation is established by the authorized Federal Executive body.

The main factor in improving the efficiency of forest reproduction should be the performance of all functions necessary to obtain the formed forest stand, including those planned in reforestation projects, measures to care for planting or for naturally renewed young forests.

The current system of forest reproduction requires the regulation of legal norms, the development of state support measures, the development and innovation activities aimed at the intensification of forestry and reforestation, in particular.

Keywords: remote sensing of the Earth, state monitoring, forest reproduction, space images reforestation activities, aerospace survey

Методические подходы к использованию данных дистанционного зондирования Земли при осуществлении государственного мониторинга воспроизводства лесов

\section{М.В. Чернов, С.М. Ханов}

Воспроизводство лесных ресурсов должно осуществляться в максимально короткие сроки наиболее эффективными в лесоводственном, экологическом и экономическом отношениях способами с учетом рационального использования земель лесного фонда, повышения продуктивности и качества лесов, обеспечения оптимальной лесистости территорий, улучшения водоохранных, защитных, санитарно-гигиенических и других полезных свойств лесов.

Ключевым фактором являются мероприятия по лесовосстановлению - деятельности по выращиванию древостоев на лесных участках, подвергшихся вырубке при заготовке древесины, а также погибших и поврежденных насаждений - регламентируемых приказом Минприроды России от 26.06.2016 № 375.

В соответствии со статьей 61.1 Лесного кодекса Российской Федерации 19 февраля 2015 года приказом Минприроды России № 59 был утвержден «Порядок осуществления государственного мониторинга воспроизводства лесов», в связи с чем возникла необходимость в разработке технических требований к материалам дистанционного зондирования Земли для решения поставленных задач. Ранее дистанционное зондирование в целях оценки хода роста лесонасаждений в Российской Федерации практически не применялось.

Государственный мониторинг воспроизводства лесов (ГМВЛ), впервые проведенный в 2015 году, осуществляется путем наблюдения с использованием наземных, авиационных или космических средств, а также путем сбора и анализа информации о воспроизводстве лесов. В настоящее время ГМВЛ является частью государственного экологического мониторинга (государственного мониторинга окружающей среды), и Порядок его осуществления устанавливается уполномоченным федеральным органом исполнительной власти.

Главным фактором повышения эффективности воспроизводства лесов должно стать выполнение всех функций, необходимых для получения сформировавшегося древостоя, в том числе, запланированных в проектах лесовосстановления мероприятий по уходу за лесными культурами или за естественным образом возобновившимися молодыми лесами.

Действующей системе воспроизводства лесов необходимо упорядочение правовых норм, разработка мер государственной поддержки, развитие инновационной деятельности, направленной на интенсификацию лесного хозяйства и лесовосстановления, в частности. 
Труды Санкт-Петербургского научно-исследовательского института лесного хозяйства № 3-4, 2018

Ключевые слова: дистанционное зондирование Земли, государственный мониторинг, воспроизводство лесов, космические снимки, лесовосстановительные мероприятия, аэрокосмическая съемка

Чернов Михаил Владимирович - заведующий конструкторским отделом

E-mail: kb@spb-niilh.ru

Ханов Сергей Маркович - начальник отдела лесного проектирования

ФБУ «Санкт-Петербургский научно-исследовательский институт лесного хозяйства» 194021, Санкт-Петербург, Институтский пр., 21

Телефон: 8 (812) 552-80-21

E-mail: mail@spb-niilh.ru 
Целью проводимых исследований является разработка технических требований к материалам дистанционного зондирования Земли для решения задач государственного мониторинга воспроизводства лесов.

В качестве объекта исследований были выделены теоретические основы и перспективы практического применения ГМВЛ, в том числе с применением средств дистанционного зондирования Земли, а также оценка мероприятий по лесовосстановлению в субъектах Российской Федерации по лесным районам.

Одной из основных задач являлось определение перспектив применения программного обеспечения, в том числе российского, для выполнения работ по ГМВЛ с подготовкой рекомендаций по использованию, созданию или доработке соответствующих программ.

Методы исследований включали в себя теоретический анализ отраслевой нормативно-правовой базы, методических указаний, отечественной и зарубежной литературы; сравнительно-сопоставительный анализ ведущих понятий и видов работ; эмпирический, структурный, функциональный и системный анализы, подробное изучение механизмов применения и практической адаптации для обозначенных целей дистанционного зондирования Земли, включая космические снимки, аэрофотоснимки.

В ходе исследовательской деятельности применялись статистические, отчетные и иные отраслевые материалы, содержащие актуальную информацию о подходах к лесоуправлению, характеристиках и динамике лесного фонда, состоянии и планируемых показателях воспроизводства лесов по рассматриваемым лесным районам, о применяемых в лесном хозяйстве геоинформационных системах (далее - ГИС), способах дистанционного зондирования Земли (далее - Д33), в том числе, для нужд ГМВЛ.

Для повышения эффективности управления лесным сектором экономики важно предусмотреть совершенствование контроля ис- полнения субъектами Российской Федерации переданных полномочий в области лесных отношений, важная роль в котором, с учетом развития геоинформационных технологий, отведена дистанционному мониторингу.

Целью дистанционного мониторинга является оценка соблюдения основных положений лесного законодательства, правил и нормативов организации лесопользования. Космическая съемка для обеспечения задач мониторинга лесов должна проводиться в весенний, летний или осенний сезоны, преимущественно в вегетационный период. Зимняя съемка при наличии снежного покрова может применяться в качестве дополнения к съемкам в бесснежный период для подчеркивания контраста некоторых объектов.

Современные средства космической съемки позволяют получать наиболее оперативную и достоверную информацию о состоянии лесов и хозяйственной деятельности на любой, самой удаленной территории, что практически недостижимо при наземных обследованиях.

С началом применения для исследования лесных насаждений спутников Д33, оборудованных оптико-электронными сенсорами сверхвысокого разрешения, использование космических снимков позволило составить конкуренцию традиционным аэрофотоснимкам в качестве исходного материала для крупномасштабного картографирования.

При рассмотрении контроля выполнения отдельных лесохозяйственных мероприятий с внедрением современных технологий можно выделить воспроизводство лесов. ГМВЛ осуществляется путем наблюдения с использованием наземных, авиационных или космических средств, а также путем сбора и анализа информации по объектам исследований, и является частью государственного экологического мониторинга (государственного мониторинга окружающей среды).

Его порядок устанавливается уполномоченным федеральным органом исполнительной власти. В соответствии с этой нормой 
Министерство природных ресурсов и экологии Российской Федерации своим приказом от 19.02.2015 № 59 [3] утвердило «Порядок осуществления государственного мониторинга воспроизводства лесов». Анализ и оценка предшествующих и современных дистанционных методов наблюдения за лесами позволяют сделать вывод о том, что пока невозможно в полном объеме заменить наземные способы обследования лесов.

Обеспечение качественного восстановления лесных ресурсов является ключевым условием сохранения лесов, выполнения ими своих биосферных функций и постоянства их использования.

Работы в сфере ГМВЛ образуют замкнутый цикл: от мониторинга характеристик партий семян и посадочного материала - к мониторингу создаваемых объектов воспроизводства лесов - мониторингу рубок ухода за лесами, а также рубок, связанных с заготовкой древесины - мониторингу земель, требующих лесовосстановления [1].

Опыт прошлых лет (60-80-е годы прошлого столетия) в развитии и совершенствовании дистанционных методов исследования природных ресурсов Земли основывался преимущественно на материалах аналоговых аэро- и космосъемок (фотосъемок).

Ранее исследования воспроизводства лесов с применением материалов Д3З практически отсутствовали или проводились в крайне ограниченных масштабах, как в нашей, так и в других странах. Фактически редки они и в настоящее время, а имеющиеся фрагментарные отечественные и зарубежные разработки поискового характера не содержат актуальных сведений о готовых практических и технологических подходах, позволяющих обеспечить производственное решение задач по осуществлению ГМВЛ дистанционным способом.

Анализ и оценка предшествующих и современных дистанционных методов позволяют сделать вывод о том, что они не могут в полной мере заменить в лесном хозяйстве наземные способы наблюдения.
Состав и количество показателей, определяемых по материалам Д33, находятся в прямой зависимости от информационных свойств, количественных и качественных характеристик конкретных данных, оперативности их получения, а, следовательно, от их рыночной стоимости. Обобщенный анализ результатов дистанционных исследований предполагает регистрацию показателей мониторинга в зависимости от их видов и характеристик для целей:

- оценки изменения площади земель, занятых лесными насаждениями (в том числе за счет естественного зарастания лесной растительностью);

- выявления земель, не занятых лесными насаждениями и требующих лесовосстановления, в том числе возникших в результате негативных воздействий на леса (засухи, пожары, паводки, ветровалы, повреждения вредными организмами и иные природные и антропогенные факторы);

- оценки качественных и количественных показателей подроста при воспроизводстве лесов.

Показателем эффективности восстановления древостоев является также динамика породного состава насаждений по группам возраста. Интенсивное ведение лесного хозяйства подразумевает переход от сугубо экономической составляющей к подходам, связанным с сохранением биоразнообразия как необходимого компонента лесной среды, с адаптацией системы лесозаготовок и лесовосстановления к методам, которые бы имитировали естественную динамику лесов [2].

В качестве приоритетных задач предусматривается улучшение породной структуры лесов, формирование технологий максимально быстрого выращивания древостоев с заданными характеристиками, включая методы ускоренного лесовыращивания и применения посадочного материала с закрытой корневой системой, повышение качества и стоимости растущего леса на корню.

Размеры нашей страны, разнообразие и 
сложность природных условий, а также огромный, постоянно расширяющийся рынок современных способов ДЗЗ подводят к очевидному заключению, что для условий России оптимальным решением задач дистанционного ГМВЛ является сочетание относительно дешевых сплошных (обзорных) методов обследования лесовосстановления (общедоступные бесплатные аэро- и фотоснимки, ограниченный перечень показателей, обзорные сведения) и выборочных (детальных) методов (высокоинформативные платные материалы Д33), расширенный перечень показателей, детализированные сведения).

Переход на использование материалов космической съемки, в том числе сверхвысокого разрешения (от 0,5 до 1 м), позволяет повысить точность работ и сократить как временные периоды, так и затраты на ортотрансформирование (геопривязку) снимков и их дальнейшую обработку вследствие отображения на космоснимках значительных по площади территорий. При масштабе 1:5000 и крупнее появляется возможность рассмотреть ширину крон, плотность расположения деревьев в древостое.

Существенным фактором является накопление в базах данных стандартизированной наземной пространственной информации о состоянии лесов, которая играет роль эталонов при оценке информативности разных видов данных, изучении дешифровочных признаков и верификации результатов работы алгоритмов автоматического дешифрирования.

Рациональное сочетание укрупненных обзорных и детальных обследований лесов дистанционными методами может быть обеспечено созданием двухуровневой (многоуровневый) системы ГМВЛ, на который ориентируются известные отечественные и зарубежные ученые.

Поэтому задачи государственного мониторинга воспроизводства лесов предлагается реализовывать на следующих двух уровнях:

- первый - сплошное обследование процессов воспроизводства лесов автоматизиро- ванными методами с ограниченным числом генеральных показателей на основе отечественных и зарубежных материалов дистанционного зондирования Земли открытого доступа (бесплатных) высокого (10 м) и среднего (30 м) пространственного разрешения по классификации, принятой в Госкорпорации «Роскосмос»;

- второй - целевое обследование процессов лесовосстановления автоматизированным путем с установленным количеством детальных показателей с учетом применения отечественных и зарубежных материалов дистанционного зондирования Земли (открытого доступа и получаемых за плату) высокого (0,5-0,6 м) пространственного разрешения по классификации Госкорпорации «Роскосмос».

ГМВЛ второго уровня с применением дистанционных методов целесообразно осуществлять в увязке с плановыми объектами и сроками выполнения лесоустроительных работ (таксации лесов дешифровочным способом).

Вышеизложенное позволяет предложить следующую концепцию осуществления ГМВЛ в Российской Федерации (рис.).

На основе проведенных исследований, с учетом имеющегося в нашей стране и за рубежом практического опыта, предлагается пошаговый алгоритм дистанционных наблюдений за воспроизводством лесов (первый уровень ГМВЛ).

\section{Этап 1. Подготовительные работы}

Шаг 1. Планирование объектов работ по ГМВЛ.

Шаг 2. Выдача госзадания на выполнение работ по ГМВЛ (с учетом наличия материалов космической съемки, соответствующих заявленным техническим требованиям).

Шаг 3. Обеспечение запланированных объектов работ по ГМВЛ материалами космической съемки.

Шаг 4. Подготовка космических снимков с уровнями обработки, соответствующими заявленным техническим требованиям. 


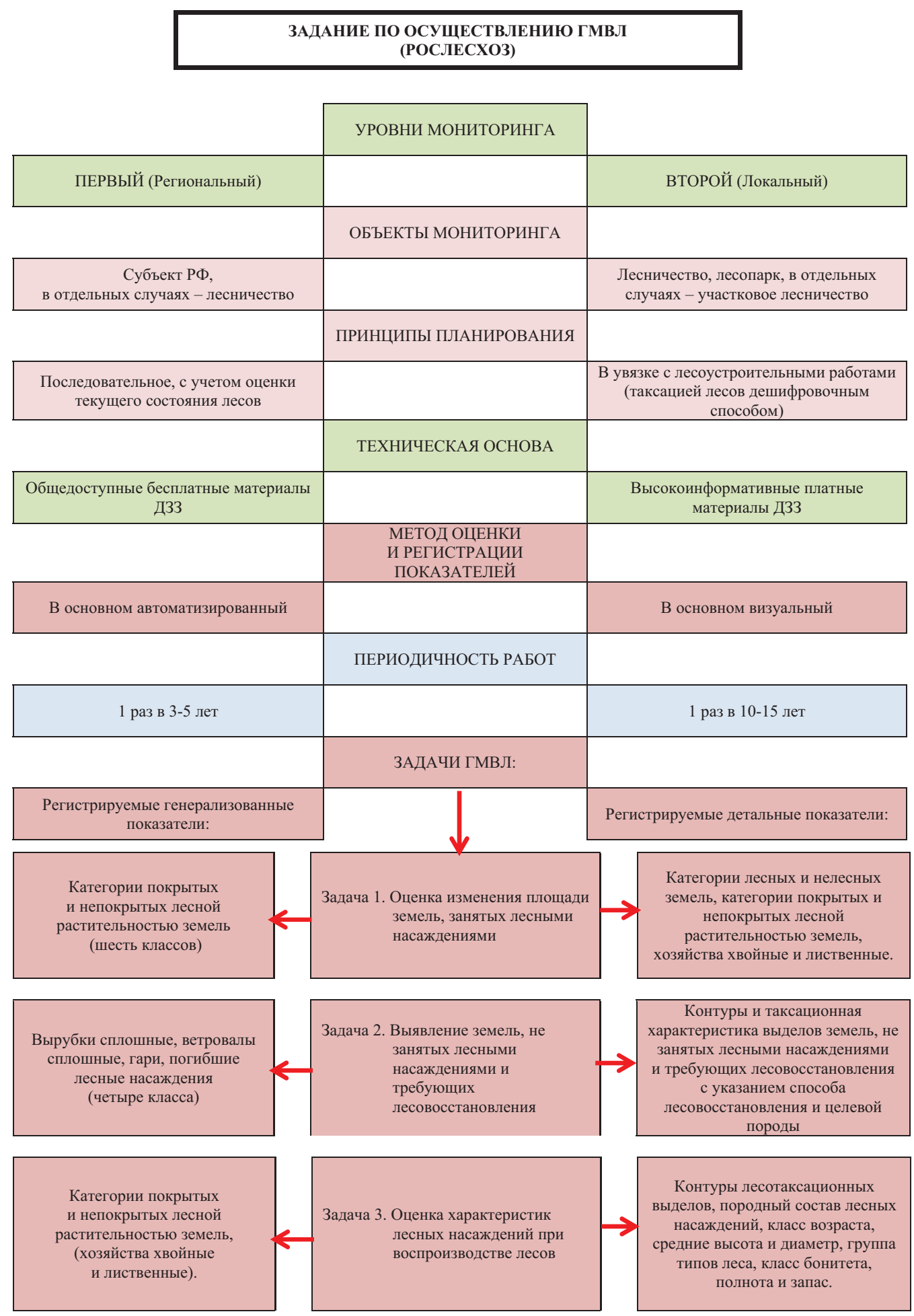

Рис. Концепция (организационно-технологическая схема) осуществления ГМВЛ в Российской Федерации 
Шаг 5. Обеспечение филиалов ФБУ «Рослесозащита» исходными материалами:

- космическими снимками с уровнями обработки, соответствующими предъявляемым техническим требованиям;

- цифровыми схемами объектов работ на поквартальном уровне;

- данными ГЛР на объекты работ по ГМВЛ.

Шаг 6. Расчет состава и объемов объектов обучающей выборки.

Шаг 7. Предварительное контурное и аналитическое дешифрирование объектов ГМВЛ.

Шаг 8. Планирование размещения объектов обучающей выборки на материалах Д33.

Этап 2. Формирование геоинформационных баз данных дистанционных наблюдений за процессами лесовосстановления и воспроизводства лесов

Шаг 9. Определение характеристик объектов обучающей выборки ГМВЛ с анализом признаков дешифрирования объектов ГМВЛ (в ходе полевых работ или по данным государственного лесного реестра).

Шаг 10. Эталонная классификация объектов обучающей выборки ГМВЛ по спектральным характеристикам (для целей автоматического дешифрирования объектов ГМВЛ).

Шаг 11. Автоматизированный (интерактивный) камеральный анализ признаков дешифрирования объектов ГМВЛ по материалам ДЗ3.

Шаг 12. Автоматизированная (интерактивная) разработка таблиц признаков дешифрирования объектов ГМВЛ с оценкой расчетных погрешностей дешифрирования.

Шаг 13. Контурное и аналитическое дешифрирование объектов ГМВЛ по материалам космических съемок (автоматизированное или автоматическое).

Шаг 14. Составление рабочих ведомостей-характеристик объектов ГМВЛ.

Шаг 15. Формирование геоинформационных баз данных объектов ГМВЛ.

\section{Этап 3. Подготовка и выпуск сдаточных материалов}

Шаг 16. Составление ведомости «Государственный мониторинг воспроизводства лесов. Характеристика лесов» (форма № 1) - сравнения данных дистанционных наблюдений за процессами лесовосстановления, воспроизводства лесов и данных ГЛР.

Шаг 17. Составление обзорной картысхемы объекта работ с отображением объектов ГМВЛ.

Шаг 18. Подготовка отчета.

Этап 4. Сдача материалов заказчику. Рассмотрение результатов работ. Принятие управленческих решений

Шаг 19. Подготовка сводного отчета о выполненных работах.

Шаг 20. Сдача работ Рослесхозу.

Шаг 21. Рассмотрение результатов работ. Принятие управленческих решений по результатам дистанционных наблюдений за процессами лесовосстановления и воспроизводства лесов с принятием предложения по разработке рекомендаций субъектам РФ по внесению изменений в ГЛР.

Пошаговый алгоритм дистанционных наблюдений за воспроизводством лесов второго уровня ГМВЛ (таксация лесов дешифровочным способом) определен действующей лесоустроительной инструкцией (2018) [4].

При выборе программного и аппаратного обеспечения для обработки материалов дистанционного зондирования учитывались следующие критерии, значимые для выполнения лесного стереодешифрирования:

- возможность формирования стереопар спектрозональных цифровых изображений;

- возможность стереоскопического просмотра материалов ДЗ3 с выполнением измерений высот, размеров крон деревьев, промежутков между ними, определением количества деревьев и степени сомкнутости полога, других геометрических показателей;

- возможность создания и редактирования векторных слоев. 
Перечисленные критерии относятся и к программному (возможность конкретной программы решать требуемые задачи) и к аппаратному (возможность работы в стереорежиме, поддержка оптимальной производительности работы с материалами ДЗЗ в сетевом режиме) обеспечению.

Установлено, что оптимальными средствами для выполнения работ по лесному стереоскопическому дешифрированию являются программы, предназначенные для цифровой фотограмметрической обработки материалов дистанционного зондирования Земли. Фотограмметрические программы позволяют выполнять работы по лесному стереодешифрированию с использованием стереопар аэроили космоснимков.

Программы фотограмметрической обработки материалов ДЗ3 применяются в производственных масштабах во многих отраслях деятельности по всему миру. Публикации результатов опытно-экспериментальных работ по лесному дешифрированию с применением фотограмметрического программного обеспечения, проводимых в России, Белоруссии, Хорватии демонстрируют положительные перспективы развития данного направления. Лесное дешифрирование с использованием фотограмметрического программного обеспечения подразумевает организацию оборудованных специальным программно-аппаратным обеспечением рабочих мест, на которых подготовленные специалисты (таксаторы-дешифровщики) выполняют работы по контурному и аналитико-измерительному дешифрированию лесов в стереорежиме. Основные отличия от «традиционного» лесного дешифрирования аналоговых материалов съемки с использованием стереоскопов состоят:

- в исключении ряда операций по подготовке материалов съемок к дешифрированию (печать снимков, взаимное ориентирование снимков, выполнение специальных измерений и вычислений для подготовки снимка к дешифрированию, ограничение рабочей площади снимков);
- в изменении ряда операций по дешифрированию и камеральной обработке результатов дешифрирования (оконтуривание выделов гуашью, сканирование фотоабрисов, трансформирование растровых изображений на слои цифровых картографических основ, векторизация фотоабрисов в ГИС);

- в оптимизации камерального цикла дистанционных наблюдений за процессом лесовосстановления и воспроизводства лесов за счет выполнения на одном рабочем месте комплекса операций (контурного и аналитико-измерительного дешифрирования с созданием векторного слоя границ лесотаксационных выделов с адресными атрибутами);

- в возможности контролирования исполнителей-дешифровщиков (при сетевой схеме функционирования цифровой фотограмметрической станции руководитель может оценивать качество и текущее состояние деятельности со своего рабочего места, выполнять контрольное дешифрирование с просмотром материалов ДЗ3 в стереорежиме и выполнением промеров высот и расстояний);

- в минимизации геометрических ошибок, связанных с преобразованиями формируемых картографических данных - результатов контурного дешифрирования, выполняемого на основе высокоточных цифровых материалов Д33 средствами фотограмметрического программного обеспечения в единой системе координат и проекций, в итоге получают векторные слои с границами кварталов и выделов, элементами картографической основы, далее экспортируемые в ГИС.

Важнейшим для фотограмметрических программ качеством является их универсальность - возможность работы с материалами разных дистанционных съемок (космические, лазерные, авиационные, съемки с беспилотных летательных аппаратов).

На основании анализа фактического состояния лесовосстановительных мероприятий по регионам России, нормативно-правовых актов, регулирующих лесовосстановление, предложены оптимальные соотношения ис- 
кусственного и естественного лесовосстановления по ряду областей.

Воспроизводство лесных ресурсов должно осуществляться в максимально короткие сроки наиболее эффективными в лесоводственном, экологическом и экономическом отношениях способами с учетом рационального использования земель лесного фонда; повышения продуктивности и качества лесов; обеспечения оптимальной лесистости территорий; повышения водоохранных, защитных, санитарно-гигиенических и других полезных свойств лесов для выполнения ими средозащитных и средообразующих функций.

Определение оптимального соотношения между естественным, искусственным и комбинированным лесовосстановлением в различных природно-производственных условиях является ответственной задачей.

Разработанные технические требования к материалам дистанционного зондирования Земли позволяют выработать правильные качественные критерии при приобретении материалов Д33, которые необходимы для решения задачи ГМВЛ, в соответствии с уровнями государственного мониторинга. При этом государство получает возможность организации двухуровневого дистанционного объективного контроля воспроизводства лесов.

Технологию работ по организации дистанционных наблюдений с получением выходных форм при осуществлении дистанционного мониторинга воспроизводства лесов обеспечивают рекомендуемые программные средства преимущественно российского производства.

В совокупности с соответствующим специализированным аппаратным обеспечением организуется автоматизированное рабочее место (далее - АРМ) исполнителя работ АРМ таксатора-дешифровщика, являющееся базой получения показателей и характеристик воспроизводства лесов по уровням дистанционных наблюдений при осуществлении дистанционного мониторинга.

Можно рекомендовать на начальных этапах выполнения работ на первом уровне ГМВЛ использовать широкий спектр программ, способных решать типовые задачи автоматического дешифрирования.

В процессе апробации и производственного внедрения технологии работ, рекомендуется выполнять сравнительную оценку используемых программ по совокупности критериев (способности выполнять решаемые задачи, стоимости, возможности выполнения операций импорта-экспорта в используемые в отрасли форматы данных, соответствие требуемым аппаратным ресурсам, совместимости с используемым в отрасли программным обеспечением и иным критериям).

Действующей системе воспроизводства лесов необходимы упорядочение правовых норм, разработка мер государственной поддержки, развитие инновационной деятельности, направленной на интенсификацию лесного хозяйства и лесовосстановления. Цикл лесовосстановительных мероприятий должен базироваться на научно обоснованном комплексе проектов и технологий создания лесных насаждений на базе оптимальных моделей воспроизводства лесов различного целевого назначения, экономической, экологической и социальной значимости.

Разработанные технические требования к материалам дистанционного зондирования Земли позволяют выработать правильные качественные критерии при выборе и приобретении материалов Д33, необходимых для скорейшего решения задач ГМВЛ. При этом государство получает возможность организации дистанционного объективного контроля воспроизводства лесов. 


\section{БИБЛИОГРАФИЧЕСКИЙ СПИСОК}

1. Государственный мониторинг воспроизводства лесов // ФБУ «Российский центр леса»: Офиц. сайт / ФБУ «Российский центр леса». - Электрон. дан. - Режим доступа: http://www.rcfh.ru/14_05_2015_ c165d.html, свободный. - Загл. с экрана. - Яз. рус. - Дата обращения: 20.06.2018.

2. Концепция интенсивного использования и воспроизводства лесов / ФБУ «СПбНИИЛХ». - СПб.: СПбНиИлХ, 2015. - 16 с.

3. Об утверждении порядка осуществления государственного мониторинга воспроизводства лесов: Приказ Минприроды России от 19.02.2015 № 59, Москва: зарегистрировано в Минюсте России 12.10.2015 № 39300 // КонсультантПлюс: Официальный сайт компании «КонсультантПлюс» / Компания «КонсультантПлюс». - Электрон. справ. правовая система. - Режим доступа: http:/www.consultant.ru/document/ cons_doc_LAW_185523/, свободный. - Загл. с экрана. - Яз. рус. - Дата обращения: 03.08.2018.

4. Об утверждении Лесоустроительной инструкции: Приказ Рослесхоза от 20.03.2018 № 122, Москва: зарегистрировано в Минюсте России 20.04.2018 № 50859 // КонсультантПлюс : Официальный сайт компании «КонсультантПлюс» / Компания «КонсультантПлюс». - Электрон. справ. правовая система. Режим доступа: http://www.consultant.ru/document/cons_doc_LAW_296757/, свободный. - Загл. с экрана. - Яз. рус. - Дата обращения: 03.08.2018.

\section{REFERENCES}

1. Gosudarstvenny monitoring vosproizvodstva lesov. FBU "Rossysky tsentr lesa", Ofits. sayt. http://www.rcfh. ru/14_05_2015_c165d.html. (In Russian)

2. Kontseptsiya intensivnogo ispolzovaniya i vosproizvodstva lesov, St.-Petersburg, 2015, 16 p. (In Russian)

3. Ob utverzhdenii poryadka osushchestvleniya gosudarstvennogo monitoringa vosproizvodstva lesov: Prikaz Minprirody Rossii ot 19.02.2015 № 59, Moskow, KonsultantPlyus, Ofitsialny sayt kompanii "KonsultantPlyus". Kompaniya "KonsultantPlyus". http://www.consultant.ru/document/cons_doc_ $L A W_{\text {_ 185523/. (In Russian) }}$

4. Ob utverzhdenii Lesoustroitelnoy instruktsii: Prikaz Rosleskhoza ot 20.03.2018 № 122, Moskow, KonsultantPlyus: Ofitsialny sayt kompanii “KonsultantPlyus”. http://www.consultant.ru/document/cons_doc_ $L A W \_296757 /$. (In Russian) 